\title{
Serum biomarkers to predict clinical response in proof-of-concept trials in spondyloarthritis
}

\author{
Maureen Turina*, Nataliya Yeremenko, Jacqueline Paramarta, Bernard Vandooren, Paul Peter Tak, Leen De Rycke, \\ Dominique Baeten
}

From 6th European Workshop on Immune-Mediated Inflammatory Diseases

Nice, France. 23-25 November 2011

\section{Background}

With TNF-blockers availability for spondyloarthritis (SpA), evaluation of new drugs requires quick "go/no go" signals in small scale, short term proof-of-concept (PoC) trials. Biomarkers complementing clinical evaluations may help reducing length and size of these PoCs. We aimed to identify and validate serum biomarkers to predict clinical response at group level in these trials.

\section{Methods}

Matrix metalloproteinase-3 (MMP-3), Pentraxin-3 (PTX3 ), high sensitive C-reactive protein (hs-CRP), calprotectin, Interleukin-6 (IL-6), Vascular Endothelial Growth Factor (VEGF), and alpha-2-macroglobulin (alpha-2-MG) were selected as biomarkers [1-3]. Serum levels were determined by ELISA in healthy controls $(n=20)$ and at week 0 and 2 in SpA patients treated with infliximab $(5 \mathrm{mg} / \mathrm{kg}$; week 0, 2, and 6) $(n=18)$ or placebo $(n=19)$. Patient and physician global assessment of disease activity and BASDAI were evaluated at week 0 and 12 .

\section{Results}

Baseline serum levels of PTX-3, hs-CRP, calprotectin and VEGF (all $\mathrm{p}<0.001$ ) were increased in SpA compared to healthy controls, whereas no differences were observed for IL-6 and alpha-2-MG. Clinical evaluation at week 12 showed that infliximab but not placebo decreased disease activity $(p<0.005)$. Accordingly biomarker levels remained stable in the placebo group. In contrast, a decrease of hsCRP ( $\mathrm{p}<0.0001)$, calprotectin ( $<<0.001)$, and IL-6 ( $\mathrm{p}=0.04)$ was observed two weeks after infliximab initiation, with a similar trend for MMP-3 $(\mathrm{p}=0.063)$. Other biomarker levels were not significantly modulated. The Standardized
Response Mean (SRM), reflecting the predictive value at the group level, was high for calprotectin $(\mathrm{SRM}=1.259)$ and good for hs-CRP (SRM=0.746) and MMP-3 $(\mathrm{SRM}=0.521)$. At individual level, linear regression revealed low correlations of changes in hs-CRP $\left(\mathrm{r}^{2}\right.$ between 0.24 and 0.36$)$ and calprotectin $\left(r^{2}\right.$ between 0.08 and 0.19 ) at week 2 with clinical outcome parameters at week 12 .

\section{Conclusion}

Early changes in serum calprotectin, hs-CRP, and MMP-3 showed a good ability to predict longer term clinical response in SpA at group level. These biomarkers are currently being validated in independent $\mathrm{PoC}$ trials.

\section{Published: 23 November 2011}

\section{References}

1. De Rycke L, Baeten D, Foell D, Kruithof E, Veys EM, Roth J, et al: Differential expression and response to anti-TNFalpha treatment of infiltrating versus resident tissue macrophage subsets in autoimmune arthritis. $J$ Pathol 2005, 206:17-27.

2. Kruithof E, De Rycke L, Vandooren B, De Keyser F, FitzGerald O, McInnes I, et al: Identification of synovial biomarkers of response to experimental treatment in early-phase clinical trials in spondylarthritis. Arthritis Rheum 2006, 54:1795-1804.

3. Vandooren B, Kruithof E, Yu DT, Rihl M, Gu J, De Rycke L, et al: Involvement of matrix metalloproteinases and their inhibitors in peripheral synovitis and down-regulation by tumor necrosis factor alpha blockade in spondylarthropathy. Arthritis Rheum 2004, 50:2942-2953.

doi:10.1186/1479-5876-9-S2-P37

Cite this article as: Turina et al:: Serum biomarkers to predict clinical response in proof-of-concept trials in spondyloarthritis. Journal of Translational Medicine 2011 9(Suppl 2):P37. 